\title{
The Challenges Confronting Computerized Health Records System Performance of the Pentecost Hospital, Accra: A Qualitative Study
}

\author{
Charles Owusu-Aduomi Botchwey, \\ University Of Education, Winneba, Faculty Of Science Education, \\ Department Of Health Administration And Education, Winneba, Ghana
}

Doi:10.19044/esj.2022.v18n3p112

Submitted: 02 April 2021

Accepted: 26 December 2021

Published: 31 January 2022
Copyright 2022 Author(s)

Under Creative Commons BY-NC-ND 4.0 OPEN ACCESS

Cite As:

Botchwey O.A.C., (2022). The Challenges Confronting Computerized Health Records System Performance of the Pentecost Hospital, Accra: A Qualitative Study European Scientific Journal, ESJ, 18 (3), 112.

https://doi.org/10.19044/esj.2022.v18n3p112

\section{Abstract}

Background: Despite the use of computerized health records systems, its application is fraught with several obstacles, which slow down the pace of operations in Pentecost Hospital in Accra in Ghana.

Aim: This study was designed to identify the challenges confronting the Computerized Health Records System performance of the Pentecost Hospital in Accra in Ghana.

Methodology: The study espoused a qualitative method with a case study design through a well-structured interview guide and focus group discussions. In all, forty-five (45) respondents including ten (10) principal informers who were purposely selected due to their interest in the performance of the Computerized Health Records System at the Pentecost Hospital in the La Nkwantanang Madina Municipality took part in the study.

Results and discussion: The study found that the introduction of the computerized health records system was faced with several challenges and they included inadequate knowledge about computerized health records systems, the breaks in internet connections of the systems, and the like.

Recommendation: Effective monitoring mechanisms, provision of adequate financial and economic resources and the involvement of all the stakeholders in providing quality and efficient computerized health record 
systems as well as the provision of adequate training are key recommendations for improving the performance of the system.

Conclusion: It is good to mention that efficient application of a computerized health record system which is geared towards efficient quality healthcare would flourish when parity, effectiveness, efficiency, and responsiveness of resource utilization for quality healthcare are considered as the building blocks.

Keywords: Computerized, health records, healthcare, system performance

\section{Introduction}

The skill of information handling, storing and recovery are self-same important to the operationalization and performance of institutional planning. This is more decisive in the health sector where precision and suitability of healthcare users' records are indispensable in improving efficacy and proficiency in identification, management, and redeemable lives. Patients' histories are critical documents that gather facts about patients' lives and wellbeing. These apprehend data on past and present health conditions and management inscribed by health care professionals caring for the healthcare users (WHO, 2006). The idea of computerized records "refers to records that are dependable on relevant machines for access or reading, that is, computer hardware and software such as e-mails, database, and word processing" (Tafor, 2003).

Information of the file, capability to get it on time, and suitability of patients' medical histories at the right time aid in no small way to save lives and to prevent health hitches. This point has been abridged by Thomas (2009) that "poor records mean poor defense, no records mean no defense." He explained that patients' histories contain a multiplicity of records of patients' histories, medical results, diagnostic test results, preoperative care, operation notes, post-operative care, daily notes of patients' progress and medications. Typically, patients' records serve four key functions: administrative, which includes demographic and socio-economic data; legal which includes a signed consent for treatment by appointed doctors and authorization for the release of information; financial, which relates to the payment of fees for medical services and hospital accommodation and most importantly, clinical on the patient, whether outpatient or emergency patient (WHO, 2006). On the financial aspect, Thomas (2009) provides that patients' record-keeping is that the increasing use of medical insurance for treatment makes the insurance companies at times require proper record-keeping to prove the patients' demand for medical expenses and that improper record keeping can result in declining medical claims and challenges. 
However, the traditional way of capturing, storing, accessing, and retrieving patients' records at the health facilities in many cases creates some challenges to health professionals and puts patients in a more or less 'dangerous' mood. For instance, Chauke (2008) observes that medical specialists at Nkhesani Hospital in South Africa found it very difficult to carry out a surgical operation on a patient because of 'a missing file'. This patient had been a victim of a car accident in the year 2005 and had a partially paralyzed leg and needed to be operated on. What appears to be much more problematic with the traditional patient record-keeping is that papers could easily get mixed up and might not be found at the time it is needed most.

With people's health and lives at stake, such explanations cannot be endured because as good as one tries to put it, it can never cater for the worsening medical situation of a patient whose records got missing. From the foregoing, it suggests that appropriate patient records keeping is important for proper medical dispensation, while poor patient record-keeping may result in high patient complications and even loss of lives. For instance, it has been noted that almost $80 \%$ of complications that occur in health facilities are a result of inaccurate information in medical records, inaccessible records, mislabeled specimens, and misfiled or missing charts (U.S. Department of Health and Human Services, 2006).

Coming to the recognition that patient medical records handling is a hub to medical processes and effective healthcare. Scholars and practitioners have advocated a need to adopt more effective, accurate, and just-in-time processes of capturing, storing, and retrieving patient information. Barry (2001) suggests that organizations need to come up with an electronic system to comply with and implement electronic records management as a necessity. It is a good clarion call that would not only enable improvement in health care options but would, in the long run, result in efficiency, in terms of money, time, and energy to ensure speedy and more interactive service delivery. For instance, the web-based personal medical records (PMR) enable health professionals, 'via interaction and contra-indication checks' to engage with patients in lifelong health information coordination and access to both patients and health service providers (Clarke \& Meiris, 2006).

In Ghana, many health facilities have begun to adopt computerized health records management to improve upon service delivery. Despite the benefits healthcare organizations derive from computerized health records systems, its application is bedeviled with several obstacles and it is on this basis that this study seeks to assess the challenges confronting computerized health records systems and the way forward at the Pentecost Hospital in the La Nkwantanang Madina Municipality in the Greater Accra Region in the Republic of Ghana. The study seeks to identify the key challenges that confront the computerized 
health records system management process at the La Nkwantanang Pentecost Hospital in Accra.

\section{Methodology}

The study employed a qualitative method with a case study design. Qualitative research encompasses gathering and evaluating non-numerical evidence. The study used both primary and secondary sources of data. In this research, primary data were collected through a well-structured flexible interview guide and focus group discussions of five respondents in each group of eight to collect data. The study population was the entire Pentecost Hospital Community and the sample size was forty-five (45). The researcher employed purposive sampling techniques to select staff in the ICT department and staff in management positions such as unit heads and supervisors who were deemed to be more knowledgeable in the topic under investigation.

In this qualitative study, the researcher employed tools such as stenography, grammarly, quetext, field notebook, and audio recorder. The stenography assisted the researcher to record the responses of respondents in the shorthands to enable the interview process to move faster than expected without necessarily writing long sentences. Grammarly helped in identifying spelling mistakes and equally correcting grammatical errors during the report writing. The quetext helped to determine plagiarised contents and worked towards their rectification. Additionally, all ethical considerations were highly observed.

In using the in-depth flexible interview guide, questions were based on the main specific objective. Permission was sought from respondents to record the interview between the researcher and the respondents and where respondents declined to be recorded, field notes were taken. To enrich responses from the respondents, a focus group discussion method was added to the individual interviews, resulting in data triangulation.

\section{Results And Discussion}

\subsection{Identify the key challenges that confront the computerized health records system management process at the La Nkwantanang Pentecost Hospital in Accra.}

\subsubsection{Challenges of computerized patient health record management systems.}

Challenges are bound to occur in the implementation and the use of Computerized Health Records Systems. The Computerized Health Records advancement in Africa, to which Ghana is a part according to Akanbi et al. (2012), Garavand et al., (2015), as well as Khalifahsoltani \& Gerami (2010) has had challenges owing to the structural, functional and social deficits peculiar to many developing countries. Hoffman et al. (2008) lamented that 
increasingly complex software heightens the likelihood of software failure. In this study, interviewees expressed the misgivings they faced when using the computerized health records system(CHRS). For instance, one interviewee said:

Computation problems, re-programming of software, hitches in the software were some of the challenges of the system $(R 1)$.

In terms of the computation problems, Koyner (2012) asserted that users were sometimes unable to analyze or understand its computation. Sittig \& Singh (2011) also noted how some features are used inappropriately by users as a result of their lack of education or training and controls which often lead to incorrect documentation of medical records.

Another challenge that strongly came out was the unreliable power supply. Apenteng (2018) noted that the intermittent power supply is popularly known as "Dumsor" meaning "off and on" of electricity affects the general health care delivery system since these CHR systems require a constant supply of electricity to function. One respondent mentioned power outages as a major problem with regard to the use of the CHR system. The power outages offset the operations of the CHR system, frustrate the users, and may damage the system. This phenomenon also affects beneficiaries of the service. Individuals who patronized the service when asked if the use of the CHR had affected their bill, they said the electricity had caused it to go high; the bill had become higher than normal; the computers they were using made it high, and there was an increase from $0.50 \mathrm{p}$ to $1.00 \mathrm{p}$. These reports were true since it mitigated the problem caused by the poor power supply, many health centers, and hospitals acquired generators and fuelled them. This creates an increase in the operational cost. More often than not, the cost incurred during this process is transferred to individuals who patronize their services. If this challenge persists they may revert to the paper-record system. One respondent said that: Halts activities in the hospital, resort to manual usage, and loss of information (R 22).

As espoused by Tchao et al (2019), the implementation of the ICT and Telemedicine project has been hampered by poor internet services. The poor network connectivity delay impacts the health delivery system and increases operation costs. (Bedeley \& Palvia, 2014; Swinfen \& Swinfen, 2002). This stalls the information flow within and between departments. The study gathered that this puts a financial burden on the hospital as espoused by one respondent that

Cost financial burden to the hospital, time involved to get the issue solve affect the organization's operations $(R 7)$.

Furthermore, another respondent said that when the system is down it puts pressure on the hospital and delays the work of the hospital. 


\subsubsection{Inadequate knowledge in managing the system}

The preliminary study revealed that despite the benefits the health facility had derived from the introduction of the Electronic Health Records System, the system still posed several challenges to the personnel of the Pentecost Hospital in particular and the activities of the hospital in general. The study identified that some of the challenges ranged from system failure through inadequate knowledge in managing the system to cost of operation. The study revealed that the introduction of the CHR was faced with several challenges and notable among them was inadequate knowledge in managing the CHRS. The study observed that even though the majority of the personnel had received training in using the CHRS, some still showed a level of deficiency when it came to managing and updating the system. The study explained that the absence of the system administrator often delayed the retrieval of patients' data. Sometimes, patients needed to wait for long hours in queues to wait for the reactivation of the system and such situations usually increased delivery time and often aggravated some patients' health conditions. The study identified that:

During the introductory stages of the CHRS, it took a long time before the majority of the personnel became used to it and this was because some of them lacked knowledge in managing the system, during power outages and updating new documents ( $R$ 37).

\subsubsection{Breaks in the network connections of the system}

The study further revealed that the breaks in the network connections of the system, hitches in the software, system breakdown, and data storage problems were some of the technical challenges bedeviling the introduction of the CHRS of the Pentecost Hospital. The study explained that technical problems with the software and the poor intermittent network issues usually delayed data entry of the hospital.

A respondent in the ICT department explained that when the network became very poor, the staff were compelled to use the paper-record keeping system. This unfortunate situation normally put a lot of workload on the few staff doing the data entry, especially, when the data to be entered were voluminous. The respondent added that the staff would have to input all those data documented on papers into the CHRS after the system had returned to normality. The respondent alleged that when the system was overburdened, it usually became too slow to operate.

Personnel in the ICT department lamented that:

Sometimes when the structure is not there, information cannot be captured and the health facility will put it in the manual form and due to this, the information will be lost, and the server makes sharing of information very difficult ( $R$ 12). 
A manager at the facility explained that the hospital had had to battle with some of these challenges especially during the times when the network had become very poor. The manager mentioned that the CHRS of the hospital usually went off in times when network connectivity had been very slow. He whispered:

The system becomes slow and goes down when there is pressure $(R 3)$.

\subsubsection{Cost of operation}

A key informant of the facility, on his part, added that the cost of operation had become one of the key challenges of using the CHRS. He explained that even though, the facility had benefited largely from the introduction of the CHRS, the monetary investment into the cost of operation had always been very high. He indicated that the facility had invested much money into the introduction of the system through recruiting system administrators, training them, paying their salaries and allowances, fueling the machines, and meeting other overhead costs.

\subsubsection{Unstable power supply}

A nurse at the facility explained that the unstable power supply was one of the reasons that led to the increase in the cost of operation. She explained that the hospital had to look for an alternative power supply using a generator. She added when there were power outages, they could halt the operations of the facility. She intimated that:

When there are power outages, they halt the activities of the hospital and the hospital will resort to manual data entry and usage and can lead to loss of information ( $R$ 29).

The study further observed that one of the many challenges confronting the introduction of the CHRS was the financial burden it had had on the hospital and the time involved in getting the issue resolved. The study identified that the cost of operating the ICT system had always been very high and had usually affected the profitability of the facility. The study added that when the cost of operation was very high, it reduced the productivity of the hospital and subsequently affected the profit margins.

\section{Conclusion}

This study was carried out at the Pentecost hospital in Accra, Ghana to investigate the challenges confronting computerized health records system performance. The study revealed that computation problems, re-programming of software, hitches in the software, unreliability of power supply, poor internet services and inadequate knowledge in managing the system, cost of operations were among the main challenges confronting computerized health 
records systems of hospitals. After the introduction of the CHR, the hospital recorded some levels of improvement in the healthcare delivery system and management but there are challenges. Poor internet connectivity and system malfunction were identified in the study as the challenges confronting the system posed. These challenges have the potential to derail the otherwise expected benefits of the computerized health records system. It is, therefore, recommended that management takes steps to eliminate these challenges or find ways to mitigate the effects of these challenges on the performance of the system. For instance, management could create alternatives like the use of an emergency power plant due to an irregular power supply. Moreover, effective monitoring mechanisms, provision of adequate financial and economic resources, and the involvement of all the stakeholders in providing quality and efficient computerized health record systems as well as the provision of adequate training are key recommendations for improving system performance amidst the identified challenges.

\section{References:}

1. Akanbi, M. O., Ocheke, A. N., Agaba, P. A., Daniyam, C. A., Agaba, E. I., Okeke, E. N., \& Ukoli, C. O. (2012). Use of electronic health records in sub-Saharan Africa: progress and challenges. Journal of Medicine in the Tropics, 14(1), 1.

2. Apenteng, B. A., Opoku, S. T., Ansong, D., Akowuah, E. A., \& Afriyie-Gyawu, E. (2018). The effect of power outages on in-facility mortality in healthcare facilities: evidence from Ghana. Global Public Health, 13(5), 545-555

3. Barry, R.E. (2001). Electronic document and records management systems - towards a Methodology for requirements definition.

4. Bedeley, R., \& Palvia, P. (2014). A study of the issues of E-health care in developing countries: The case of Ghana.

5. Chauke, O. (2008). No operation as patient file is lost. Capricorn Voice 10-12 September: 7. Clarke, J. L., \& Meiris, D. C. (2006). Electronic personal health records come of age. American Journal of Medical Quality, 21(3 suppl), 5S-15S.

6. Garavand, A., Samadbeik, M., Kafashi, M., \& Abhari, S. (2016). The identification and classification of deployment challenges related to electronic health records: a review article. Shiraz E Medical Journal, 17(2), e33304.

7. Graetz, I., Huang, J., Brand, R., Shortell, S. M., Rundall, T. G., Bellows, J., ... \& Reed, M. E. (2015). The impact of electronic health records and teamwork on diabetes care quality. The American Journal of Managed Care, 21(12), 878. 
8. Hoffman (2008). Finding a cure: The case for regulation and oversight of electronic health record systems. Harvard Journal of Law and Technology, 22(1).

9. Reed, M., Huang, J., Brand, R., Graetz, I., Neugebauer, R., Fireman, B., ... \& Hsu, J. (2013). Implementation of an outpatient electronic health record and emergency department visits, hospitalizations, and office visits among patients with diabetes. Jama, 310(10), 1060-1065.

10. Sittig, D. F., \& Singh, H. (2011). Defining health information technology-related errors: New developments since to err is human. Archives of Internal Medicine, 171(14), 1281-1284

11. Swinfen, R., \& Swinfen, P. (2002). Low-cost telemedicine in the developing world. Journal of Telemedicine and Telecare, 8(3_suppl), 63-65.

12. Tafor, V. (2003) Digital technology- Understanding the problems posed by Information Technology in generating and managing records from a third perspective. ESARBICA Journal, 22, 72-77.

13. Tchao, E. T., Acquah, I., Kotey, S. D., Aggor, C. S., \& Kponyo, J. J.(2019) On Telemedicine Implementations in Ghana.

14. Thomas, J. (2009). Medical records and issues in negligence. Indian Journal of Urology: IJU: Journal of the Urological Society of India, 25(3), 384.

15. World Health Organization. (2006). Electronic health records: manual for developing Countries. Available online at http://www.wpro.who.int/publications/docs/EHRmanual.pdf (Accessed on January 19 ${ }^{\text {th }}$, 2020). 